\title{
Understanding the cephalopod immune system based on functional and molecular evidence
}

\author{
C. Gestal ${ }^{1} *$ and S. Castellanos-Martínez $z^{1,2}$ \\ ${ }^{1}$ Instituto de Investigaciones Marinas (CSIC). Eduardo Cabello 6, 36208 Vigo, Spain. \\ ${ }^{2}$ Present address: Departamento de Recursos del Mar, Centro de Investigación y de \\ Estudios Avanzados del IPN Unidad Mérida, Antigua carretera a Progreso Km. 6, 97310, \\ Mérida, Yucatán, México
}

*Corresponding Author:

Camino Gestal

Instituto de Investigaciones Marinas (CSIC)

Eduardo Cabello 6

36208 Vigo, Spain.

Tf. +34 986231930 Ext. 290

e-mail: cgestal@iim.csic.es 


\section{ABSTRACT}

Cephalopods have the most advanced circulatory and nervous system among the mollusks. Recently, they have been included in the European directive which state that suffering and pain should be minimized in cephalopods used in experimentation. The knowledge about cephalopod welfare is still limited and several gaps are yet to be filled, especially in reference to pathogens, pathologies and immune response of these mollusks. In light of the requirements of the normative, in addition to the ecologic and economic importance of cephalopods, in this review we update the work published to date concerning cephalopod immune system. Significant advances have been reached in relation to the characterization of haemocytes and defensive mechanisms comprising cellular and humoral factors mainly, but not limited, in species of high economic value like Sepia officinalis and Octopus vulgaris. Moreover, the improvement of molecular approaches has helped to discover several immune-related genes/proteins. These immune genes/proteins include antimicrobial peptides, phenoloxidases, antioxidant enzymes, serine protease inhibitor, lipopolysaccharide-induced TNF- $\alpha$ factor, Toll-like receptors, lectins, even clusters of differentiation among others. Most of them have been found in haemocytes but also in gills and digestive gland, and the characterization as well as their precise role in the immune response of cephalopods is still pending to be elucidated. The assessment of immune parameters in cephalopods exposed to contaminants is just starting, but the negative impact of some pollutants on the immune response of the common octopus has been reported. This review summarizes the current status of our knowledge about the cephalopod immune system that seems to be far from simply. On the contrary, the advances gained to date point out a complex innate immunity in cephalopods. 
Keywords: Cephalopods, innate immunity, cellular factors, humoral factors, immune genes/proteins, transcriptomics, proteomics, mollusks.

\section{Introduction}

Cephalopods are a small Class of the Phyllum Mollusca. Currently more than 700 species (octopuses, squids, cuttlefish and nautiluses) are recognized occupying all the world's oceans, from the intertidal areas to the deep sea. Interest in cephalopods has increased considerably in the last years, mainly because they are the subject of important fisheries with high market value. Since the decline of traditional fisheries, cephalopods have gained attention in aquaculture practice. Among cephalopods, the common octopus Octopus vulgaris and the cuttlefish Sepia officinalis are good candidate species in European aquaculture, and especially in Mediterranean countries (Spain, Portugal and Italy) because of their short life cycle and fast growth, readily adaptation to captivity conditions, high feed efficiency, high reproductive rate, and high nutritional value and market price. In America, the candidate species are Octopus maya, Octopus mimus, Robsonella fontaniana, O. vulgaris, Octopus bimaculoides and Enteroctopus megalocyathus. The aquaculture of these holobenthic and merobenthic species is still under experimentation because, as in the rest of the cephalopods, the feeding habits of paralarvae have not been resolved [1]. A state of the art of cephalopod culture today providing scientific reference for aquaculture and ongrowing different cephalopod species all around the world has been published recently [2].

Nowadays the common octopus is cultured in Spain in on-growing cages in a semi-

open system (Figure 1). This system relays on captured wild individuals but the lack of 
hatcheries that could supply with juveniles remains a major problem. Thus, to close the complete cycle in captivity is still a challenge for the aquaculture. At present, life cycle from hatching to settlement or beginning of the benthonic adult phase is not commercially viable [3] due to the paralarval high mortality. Currently special attention is focused on the optimization of octopus early stages in rearing conditions, not only for the high economical interest of their aquaculture, but also due to the requirement of the new European Directive 2010/63/EU to minimize the use of captured animals from the wild to be used in experimentation. These studies on early stages are providing relevant knowledge not only on nutritional physiology, but also on the effect of environmental stress on the immunecompetence status of paralarvae and the identification of biomarkers of welfare and health as key factors that could help to resolve successfully the culture of this species [4].

In addition, cephalopods have a high value as experimental animals for biomedical and behavioral research [5,6]. In fact, the class Cephalopoda is considered the most complex one in the phylum Mollusca and it is call as "advanced invertebrate" or “exceptional invertebrate class" [7]. They have evolved many characteristic features such as highly differentiated multi-lobular brains, a vertebrate-like eye, close circulatory system, a sophisticated set of sensory organs and fast jet-propelled locomotion [8,9] that make them interesting models for research.

\subsection{Cephalopods as subjects of the European Directive}

The recent inclusion of "all live cephalopods" in the Directive 2010/63/EU that

regulates the use of animals for scientific purposes (European Parliament and Council of 
the European Union 2010) [10] represents the first time that an entire class of invertebrates has been included in laboratory animal legislation throughout the EU. The decision was based on the evidence for sentience and capacity to experience pain, suffering, distress and lasting harm $[11,12,13]$. Until now only vertebrates have been included in the National legislation regulating experimentation on living animals. The only exception was the inclusion of the species Octopus vulgaris in a revision of the UK legislation, but no studies had been conducted under this legislation. Outside Europe, cephalopods have been included in various National legislations covering research, such as Canada, New Zealand, Australia, Switzerland and Norway [14].

The inclusion of cephalopods in the European Directive, based on the reinforcement of the 3 Rs (reduction, refinement and replacement) policy, obliges cephalopod researchers and technicians to promote the best welfare practices during aquaculture procedures, maintenance and experimentation on cephalopods. However, the lack of knowledge on different aspects of this class, including general care and principles of good practice, welfare, health and housing requirements, among others, requires the description of guidelines for different species. Currently, few references concerning ethical considerations and welfare in cephalopods used in experimentation were published [12,15]; The first guideline for the care and welfare of cephalopods in research [16] has been recently developed as a result of a joint international initiative between researchers as an interdisciplinary network of experts with the objective of improving procedures and foster scientific exchanges to integrate knowledge on welfare practices. This guideline cover topics such as implications of the Directive for cephalopod research, project application requirements and authorization process, the application of the 3Rs principles, the need for harm-benefit assessment and severity classification, as well as species specific 
requirements and scientific procedures. Although a great effort in publishing new experimental data have been observed in last years, the knowledge about cephalopod welfare is limited and scattered among laboratories, and there are gaps of scientific knowledge regarding several aspects of health assessment and well-being.

\subsection{The past and present of the cephalopod immune system}

One of the most important issues for aquaculture and also for experimental aquarium maintenance is the animal health. High population densities, animal manipulation, and culture conditions are associated with stress, which affects the immunecompetence and favors the development of infectious diseases. To avoid pathologies, a good welfare practice must be implemented at different stages of maintenance, rearing and culture of cephalopod species [17]. The identification of biomarkers of welfare, health or resistance to pathogens will help to achieve a successful and sustainable cephalopod aquaculture.

The knowledge of the most common pathogenic agents identified in cephalopods has been reviewed in the classic "Diseases of Marine Animals" with contributions by Hanlon and Forsythe 1990a, 1990b, and Hochberg [18,19,20]. Additionally, different data have been published, on virus [21,22] and bacterial infectious [23,24,25], diseases produced by protozoan parasites, specially the gastrointestinal coccidian of the genus Aggregata [26,27,28,29,30,31,32]; metazoan parasites including cestoda $[33,34,35,36]$; trematodes [37]; nematodes, specially Anisakids [38,39]; and crustaceans [33,40,41,42]. However, the research effort on the identification of pathogens and pathologies suffered by cephalopods is currently less than $54 \%$ of the effort directed to other commercially important marine resources [43]. 
Cephalopods are advanced mollusks with a close well developed circulatory system composed by veins and arteries, and with one systemic and two accessory brachial hearts which distribute the haemolymph through the body [44]. The haemocytes, the circulating cells of the haemolymph, are involved in several functions, from nutrient digestion, transport and excretion, to wound repair and immune response. The haematopoietic organ in cephalopods is the white body, the organ where the haemocytes are produced. It is located behind the eyes in the orbital pits of the cranial cartilages $[45,46]$. The function of white body was first described by Cazal and Bogoraze in 1943 [47], who reviewed the histology of this organ and supported the view that it formed haemocytes. Necco and Martin in 1963 [48] were able to grow the cells of the white body in tissue culture and noted two types of cells, one spindle-shaped and the other rounded. This feature was in accordance with the observations by Stuart in 1968 [49], who identified both phagocytic and non-phagocytic leucoblastic cells in the common octopus. However, after the studies of Cowden and Curtis [50], the statement of the presence of a single type of haemocytes in the circulating haemolymph was widely accepted.

The knowledge of immune mechanisms of cephalopods is limited. The current published data indicate that cephalopods lack adaptive response but have an effective innate system composed by cellular and humoral components. Cephalopods as other mollusks do not have an immune memory system, they do not have immunoglobulins and therefore, procedures such as vaccination cannot be used as methodologies to face diseases. Thus, the cephalopod immune system works on the basis of "cellular factors". The haemocytes respond by infiltration, encapsulation, phagocytosis, or cytotoxic activities to infections and to isolate and destroy pathogens. The elimination of pathogens by phagocytosis is 
accompanied with the production of cytotoxic activity, oxidative reactions activated in response to pathogens. This cytotoxic activity comprises the production of reactive oxygen species, the reactive oxygen intermediates (ROIs) known as respiratory burst, and nitric oxide (NO), a highly-reactive free radical and an effective agent against pathogens. In addition, humoral factors with opsonic, lytic, antimicrobial and protease-inhibition activities are present in the serum.

The most recent findings reveals that the immune system of cephalopods seems not to be as simple as believed, as correspond to animals based on innate immunity. The advances reached in morphofunctional characterization of cells, as well as identification of immune-related genes and immune pathways by similarity with other phylogenetic distant animals, using transcriptomic and proteomic approaches, indicate that cephalopods could be in the top of the molluscan immune system development, and could be considered an important link between invertebrates and vertebrates.

\section{Type and number of haemocytes in the cephalopods haemolymph}

Haemocytes are crucial in the cephalopod immune response [51,52,53]. Although these cells are vital to maintain the wellbeing in all different cephalopod species, the studies conducted about haemocytes are limited, and most of the observations have been performed on octopus species $[45,50,54,55,56,57,58]$ with few descriptions available on Euprymna scolopes [59] and Sepia officinalis [46,60,61]. In one of the first studies of characterization based on morphology and immune capability of cells, Stuart [49], identified phagocytic and non-phagocytic "leucoblastic cells" in common octopus. However, subsequent studies 
sustained that a single type of haemocyte was present in the haemolymph of cephalopods $[45,50,54]$. Such statement was widely accepted because of few descriptions of the cephalopod haemocytes were available. Nowadays, the number and type of cells in the haemolymph of cephalopods is under debate since current studies showed that more than one single type of cell is observed in the O. vulgaris haemolymph $[57,58]$. However, this statement seems not to be the same in Sepia officinalis [61].

Two different works focused on the morphological characterization of $O$. vulgaris haemocytes using light and electron microscopy, and flow cytometry (FC) showed different results. In NE Atlantic waters, two different types of cells or haemocytes were identified in the circulating haemolymph of the common octopus [57]. However, three types of cells were identified in the octopus from Mediterranean Sea [58]. The haemocytes were classified as small and large granulocytes (Figure 2) by Castellanos-Martinez et al. [57] while Troncone et al. [58] classified them as haemoblast-like cells, hyalinocytes and granulocytes. Although different classifications were established, great similarities are found between them. For instance, granulocytes (large granulocytes) were clearly defined in both studies because of their high granularity and ability to extend pseudopodia (Figure 3). However, in O. vulgaris from NE Atlantic, granulocytes are the cells with the largest size and complexity observed by FC, showing differences in diameter (9-15 $\mu \mathrm{m})$ [57] with granulocytes characterized in the same octopus species from Mediterranean Sea (5-10 $\mu \mathrm{m})$ [58]. Likewise, in O. vulgaris from Mediterranean Sea, haemoblast-like cells are characterized by low size and complexity ( $8 \mu \mathrm{m}$ average in diameter) with spherical nucleus and lacking of cytoplasm. Hyalinocytes are similar to haemoblast-like cells in diameter, but differ because hyalinocytes are round to ovoid in shape and might contain 
granules in their cytoplasm; these features locate them easily as an intermediate cell population by FC [58].The features and range of diameter observed in haemoblast-like cells and hyalinocytes agreed to the haemocytes previously classified as small granulocytes (Figure 2), which were found as a single well defined population by FC [57].

The proportion of each type of cell in the circulating haemolymph of the common octopus also showed differences between localities. Large granulocytes (or just granulocytes) were the most abundant (82\%) cells in the haemolymph of $O$. vulgaris from NE Atlantic, being the small granulocytes the less represented ones $(<20 \%)$ [57]. On the contrary, hyalinocytes and haemoblast-like cells were found in $60 \%$ and $30 \%$ respectively in the haemolymph of $O$. vulgaris from Mediterranean Sea, whereas granulocytes were the cells with the lowest proportion (10\%) [58]. Although differences in the number and proportion of cells found in the common octopus haemocytes could be attributed to the protocols established by each laboratory $[62,63]$, we should not discard the possibility of variations due to contaminants [64], environmental conditions [65], or even pathogenic infections [66] occurred in these two different sampling areas, NE Atlantic and Mediterranean Sea. Concerning pathogens, parasites affecting $O$. vulgaris have been recorded from both locations [67,68], including the coccidian Aggregata octopiana, which is recognized as the most dangerous parasite for $O$. vulgaris [28,69] showing a negative impact on the octopus immune system.

Unlike $O$. vulgaris, the observations performed by light and electron microscopy in S. officinalis haemolymph showed the presence of a single cell that possess a large nucleus U-shaped and several basophilic and acidophilic granules in the cytoplasm [61]. This single cell population is supported by FC analysis, which is characterized by their large size and 
complexity, and is also responsible to eliminate foreign particles (see below) [61]. Similarly, only one population of haemocytes of large size and complexity has been recorded in Euprymna scolopes haemolymph [59,70].

Although octopods and decapods belong to Cephalopoda, the few data available to date suggests differences in the number and type of haemocytes responsible of the immune defense in both cephalopod groups. Morphological identification is inadequate if it is not complimented with additional methods. Nowadays, FC is very valuable to characterize cells. However, cytochemical methods might also provide valuable information added to functional and morphological schemes to characterize the cells. Thus, a standard classification could be reached although, definitely, a major effort of research must be done.

The concentration of haemocytes in circulating haemolyph is an important parameter since it may be used as a biomarker of immune response capability and reflects the welfare of the individuals, as had been stated in other mollusks $[65,66]$. Specific data concerning changes in haemocyte concentration after injury or experimental pathogen injection have been published in O. vulgaris [57,71], E. cirrhosa [52,53] and S. officinalis [61]. In addition, Le Pabic 2014 [61] published a comparative table of circulating haemocyte concentration of different mollusks, including cephalopods, bivalves and gastropods. However, all these data collected in cephalopods should be carefully analyzed, and the mean basal haemocyte concentration should be standardized in healthy animals as an easy and useful tool to identify stress or diseases in cephalopods maintained in aquarium for experimentation or in aquaculture practices. This parameter will be useful to improve 
animal well-being, especially now that cephalopods are included in the new European Directive 2010/63/EU on animal protection.

\section{Functional immune defense of cephalopod haemocytes}

Cephalopods, as the rest of mollusks, rely on their innate immune system to face infections as well as every nonself material [17]. In the last five years a rising interest for understanding how these cells fight to avoid infections have been gaining attention and helped providing the newest information that is disclosing interesting findings related to cephalopod immunity.

Most of the information that we have about cephalopod diseases, apart from the necrotic analysis of individuals obtained from the fishery, comes from organisms reared to

supply specimens for aquarium maintenance or for physiological experiments. These analyses confirm that bacterial, virus and protozoa are the commonest pathogens affecting wild and reared cephalopods [23]. Squids, cuttlefishes and octopus in aquaculture facilities usually suffer skin injuries in the mantle which are advantaged for bacterial with the consequent development of infections. Cellular and humoral factors are here involved in pathogen recognition, activation and elimination of pathogens, but remain poorly studied in cephalopods to date $[17,24]$.

Beyond the protective limits that represent the skin of cephalopods, additional mechanisms are triggered to face those nonself materials that surpass such physical barrier. One of the first defensive activities carried out by haemocytes is phagocytosis of foreign particles and pathogens (Figure 4). These are subsequently destroyed through the 
production of enzymes (lysozyme) [71] as well as reactive oxygen species (ROS) and nitric oxide (NO) radicals. All of these defensive strategies have been recently studied more precisely by flow cytometry in $O$. vulgaris and S. officinalis [57,61].

Phagocytosis is one of the most important mechanisms directed to eliminate nonself materials by cell membrane invagination [67]. In bivalves and some gastropods, granulocytes are usually the cells with the highest phagocytic rate $[72,73,74,75]$. In cephalopods, the only type of haemocytes reported in S. officinalis, the granulocytes, are in charge to remove particles reaching up to $70 \%$ of phagocytosis [61]. Similarly, the $O$. vulgaris large granulocytes are the main phagocytic cells, but they seem to possess lower phagocytic ability than in $S$. officinalis since the maximum value recorded in $O$. vulgaris was $56 \%$ and, in average, $13 \%$ of large granulocytes were able to engulf particles [57]. The difference in the phagocytic ability of haemocytes between S. officinalis and O. vulgaris was attributed to methodological process (61). The opsonization is suggested by Le Pabic et al. [61] as a main factor affecting phagocytosis in the common octopus haemocytes. However, discrepancies are found in the common octopus. While Stuart [49] indicates that opsonization is important for phagocytosis, a previous study developed by Rodriguez et al. [76] recorded a phagocytosis of $52 \%$ at $15^{\circ} \mathrm{C}$ without opsonization needed. Moreover, comparing the mean number of particles engulfed by haemocytes we can find similarities between species, since a total of 18 beads were recorded inside sepia haemocytes [61] while a maximum of 20 yeast particles were engulfed by haemocytes of the common octopus [58]. These results suggest that cephalopod haemocytes have high ability to phagocytize particles of different nature and thus remark the importance of phagocytosis as a key mechanism to remove potential pathogens [61]. In addition, active phagocytic cells 
have also been described in other different organs of the common octopus, such as posterior salivary glands, gills, white body and branchial heart $[49,50]$. In cuttlefish the ovoid cells of the branchial hearts are responsible for the elimination of bacteria from the haemolymph and serve as an important detoxification system [77]. The abundance of these phagocytic cells is correlated with the protective barrier function in gills or even branchial hearts and their role in the immune defense, which coincides with significant phenoloxidase activity recorded in gills, systemic and branchuial hears that suggests a key role of these organs in the immune system of sepia [61]. However, additional information is needed to explain this immune response activity in such additional organs.

Further destruction of strange particles occurs through the yield of reactive oxygen (ROS) and nitrogen (NOS) species, respectively. In O. vulgaris, the different types of haemocytes showed different oxidative activity. Considering large and small granulocytes, the former cells yield higher cytotoxic activity than small granulocytes. Likewise, the highest activity was recorded at 60 min of incubation while the lowest values occurred at 30 and 180 min in both types of cells, suggesting that large granulocytes are more actively involved in cytotoxic defensive activities than small granulocytes [57]. The ability of each type of haemocyte to yield NO has not been assessed independently. However, it is well known that the populations of haemocytes yield higher NO radicals after stimulation using zymosan than Escherichia coli lypopolysacharide (LPS) or Phormol Myristate Acetate (PMA) [57].

In addition to the role of the cytotoxic mechanisms in the mollusk immune response, the measurement of defensive mechanisms of haemocytes is also carried out to assess the health status of mollusks in response to pollution [78] and cephalopods are being 
taken into account because of their ecological importance in the marine environment [79]. Accumulation of heavy metals is major concern for monitoring environmental health but also for food security. Experiments performed on S. officinalis eggs exposed to Ag and Cd evidenced that $\mathrm{Cd}$ is accumulated by the eggshell while Ag passed through the eggshell and more than $40 \%$ is accumulated in the embryo [80]. In addition, adult sepia exposed to metal pollution in coastal waters is able to transfer some metals ( $\mathrm{Ag}, \mathrm{Se}$, and $\mathrm{Zn}$ ) to their brood [81]. A $90 \%$ of the total metal body burden was recorded in the digestive gland, suggesting their key role in the storage [82]. Additionally, this result is coincident with high levels of metallothionein (proteins to which several metals and metalloids have a high affinity) in digestive gland, but also in gills of $O$. vulgaris providing evidence about the important role of digestive gland in the detoxification and the sensitivity to environmental conditions [83].

The immune response of mollusks is being assessed in response to pollution by nanoparticles like those of titanium dioxide $\left(\mathrm{nTiO}_{2}\right)$, widely used on industrial applications with questionable impact for human, animal and environment health [84,85]. Although the effect of nanoparticles on the mollusk immune system has not been totally understood, one of the effects resulting from nanoparticles pollution is the oxidative stress [86]. In addition, lysosomal destabilization, decrease in phagocytic activity and increase of ROS and NO production are some of the effects observed in other mollusks [87]. Concerning cephalopods, the only work available to date is the one provided by Grimaldi et al. [71] who detected by the first time that $\mathrm{nTiO}_{2}$ causes an increased in lysozyme activity and NO production in haemocytes, reaching the highest values when the highest concentration (10 $\mathrm{g} / \mathrm{ml}) \mathrm{nTiO}_{2}$ was injected to adult octopus. This work represents a first step to understand the effect of such pollutants on the cephalopod immune response. However, more research 
needs to be done in order to have a comprehensive framework about the interaction of cephalopod immunity and pollutants at functional and molecular level.

The work of Fisher and Dinuzzo [88] evidenced that antimicrobial peptides (AMPs) are part of the defensive battery of cephalopods, demonstrating their presence in the haemolymph of mollusks, including cephalopods. These proteins are important components of the humoral defenses of all species and the highest concentrations are found in tissues exposed to microorganisms [89]. In cephalopods, compounds with antimicrobial activities against clinical isolates such as Vibrio chlolerae, Escherichia coli, Pseudomonas aeruginosa or Klebsiella pnemoniae have been isolated from tissues of Sepia kobiensis, Sepiella inermis, Sepioteuthis lessoniana and Sepia brevimana even from the cuttlebone of Sepia prashadi [90,91], and the tissue of Octopus aegina, Octopus aerolatus, Octopus cyaneus and Octopus dollfusi are also a valuable source of compounds with antimicrobial activities $[90,92]$. Likewise, antimicrobicidal compounds have been extracted from the ink of Euprymna stenodactyla [93] and from the tissue and gladius of Loligo duvauceli and Doryteuthis sibogae [94]. In addition to tissues, the newest data demonstrated an effective killing activity of haemocyte crude methanolic acid extract from $O$. vulgaris against Gram positive bacteria like Staphylococcus aureus, Bacillus cereus and Lysteria monocytegenes even at low $(0.8 \mu \mathrm{g} / \mathrm{ml})$ concentration [58].

Infections derived from microbial origin triggers the activation of humoral factors like the melanization cascade, which is controlled through the activation of zymogenic prophenoloxidase (pro-PO) into active phenoloxidase (PO) [95]. High phenoloxidase and lysozyme-like activity was recorded in the integument of S. officinalis [96], and it might be 
derived to the need to control grow of the bacterial symbionts commonly found in the skin of cephalopods [24].

Additionally, high phenoloxidase-activity was found in gills (constantly exposed to the environment), but also in the digestive gland; presumably this organ could be a reservoir of phenoloxidase to fight parasites that infects the cephalopod digestive tract [96]. In line with humoral mechanisms, a high level of lysozyme (an enzyme that attacks the bacteria cell wall in order to lyse them) was expected to be found in the plasma of $S$. officinalis, but negative results were obtained. In contrast, high activity was recorded in branchial heart appendages [96] similar to those found by Malham et al. [53]. Additionally, positive results have been also obtained in $O$. vulgaris challenged with nanoparticles $\mathrm{TiO}_{2}$ (10 g/ml), particularly, $4 \mathrm{~h}$ after challenge [71]. As it was shown, most of the studies performed so far have been focused on cephalopod tissues. Therefore, more studies focused on cellular and humoral factors would help us to understand the immune mechanisms acting in cephalopods against foreign particles and pathogens.

\section{Cephalopod molecular immunity: the "omics age"}

In 2012 the interest and importance to achieve the genome of cephalopods for neurobiology, ethology, ecology, fishery and more fields of study was stated [97]. To date, the genome of any cephalopod species has not yet been sequenced, and only little steps have been done towards increase the molecular knowledge on these mollusks. Concerning the study of the cephalopod immune system, the advent of automated DNA, RNA and also protein sequencing technology has provided highly important insights about genes, proteins and pathways involved in the immune response of cephalopods, making clear that it is more 
complex than we have thought. Nowadays "omics" approaches are becoming frequently applied to disclose a wide range of biological aspects, and in cephalopods this includes also one of the topics currently with most interest, which is how the immunity of cephalopods works.

The molecular basis of the $O$. vulgaris immune system has been recently provided through a transcriptomic approach (RNA-seq using Illumina high-throughput technology) applied to the octopus haemocytes. According to this sequencing strategy, the theoretical transcriptome length of $O$. vulgaris haemocytes is $170.2 \mathrm{Mb}$. After sequencing, and assembling of high quality reads, a total of 254,506 contigs or sequences were obtained. From this, only $18.95 \%(48,225)$ of sequences matched to a significant BlastX hit. The remaining $81.05 \%$ of the assembled sequences did not match any known protein [98]. Such results give an idea about the low representation of cephalopods in public databases to date. At the same time, this result suggests that potentially novel genes might be awaiting identification and validation, including those involved in immune response. Even thought, $3 \%$ of predicted proteins related to an immune function were identified [98], a small but acceptable quantity compared to $10 \%$ recorded in bivalves like Ruditapes decussatus [99], which is presumably better represented in public databases than the common octopus.

The transcriptomic analysis of $O$. vulgaris haemocytes allowed the identification of a number of putative members of the complement (Figure 5) and NF $\kappa-B$ pathway, pattern recognition receptors (Toll-like, lectins, peptidoglycan) and antimicrobial peptides, like the bactericidal permeability-increasing protein (BPL). Some of these proteins were previously reported in cephalopods like Octopus maya [100] and Euprymna scolopes [101,102,59]. However, most of the molecules found such as those involved in apoptosis, the serine 
proteases inhibitor (SERPIN) or lipopolysaccharide-induced TNF- $\alpha$ factor were recorded for the first time in a cephalopod. Novel findings in the common octopus haemocytes corresponds to the peroxisome proliferator-activated receptors (PPARS), which is antiinflammatory and also can interact with transcription factors involved in inflammation (NF$\mathrm{kB}$, activator protein- 1 (AP-1), STAT). In addition, cluster of differentiation (CDs), cell surface molecules capable to be recognized by a group of monoclonal antibodies and associated to specific immune functions, were found. The only cephalopod species where previous CDs (CD63) was found is E. scolopes [59]. These recent findings of sequences with high similarity to specific CDs markers for proteins known to participate in vertebrate immune response, the presence of specific transcripts with high similarity to Jaw1, a protein expressed in the $\mathrm{B}$ and $\mathrm{T}$ lineages, strongly could be indicative that similar mechanisms may be occurring in phylogenetic distant animals such as cephalopods. All these results could start to reveal that immune response in cephalopods could be more complex and evolved than expected [98]. A recent study performed in Octopus ocelatus reported a new SERPIN with a molecular weight of $46.5 \mathrm{kDa}$ [103]. It is constitutively expressed in mantle, muscle, renal sac, gill, haemocytes, gonad, and systemic heart. However, the extremely significant high (760-fold) expression was recorded in the digestive gland, suggesting a probable role in immune response (in addition to their detoxification function attained) [103] as also was posed for this organ in S. officinalis [96]. The exposition of $O$. ocelatus to Listonella anguillarum $\left(1 \times 10^{7} \mathrm{CFU} / \mathrm{mL}\right)$ induced the highest (85-fold) expression of SERPIN at $48 \mathrm{~h}$ after stimulation, while Micrococcus luteus $\left(1 \times 10^{7} \mathrm{CFU} / \mathrm{mL}\right)$ induced the same high (26-fold) effect at $24 \mathrm{~h}$. Such differences are not clear, but it might be a result of differences in the immune response mechanisms activated by each bacteria species [103]. 
Regarding to pathologies, the interaction between the common octopus and the coccidian parasite Aggregata octopiana is also under study from the molecular viewpoint. Coccidiosis caused by this parasite is considered the most dangerous infection suffered by the octopus [28], which is debilitated by the damage produced by the parasite in the epithelial lumen of the digestive tract, the alteration of $\mathrm{pH}$ inside the gut that ends in malfunction of the digestive enzymes and thus, low nutrient absorption [27]. The molecular analysis of such interaction obtained by high-throughput sequencing differential analysis allowed the identification of 312 genes from a total of 539 genes differentially expressed between octopus harboring high and low parasitic load, corresponding to sick and healthy octopus respectively. It was found that the coccidiosis prompt the expression of C1q, TLR, peptidoglycan recognition patterns (PGRP) and the antioxidant peroxiredoxin in the target organ of infection, the octopus caecum. In contrast, the expression of TLR was higher in octopus with high parasitic load than those low infected. Presumably, it is because haemocytes are able to detect parasite-derived ligands that in turn trigger the inflammatory response. However, it seems that coccidiosis suppress also the expression of PGRP, the C1q binding protein and the expression of the antioxidant peroxiredoxin [98]. Functional assays have shown that a decrease in the oxidative activity of haemocytes correlates with the increase of coccidiosis in O. vulgaris [69]. Thus, a low transcription and weak protein expression of peroxiredoxin (Figure 6) is reported in octopuses with high parasitic load [57,104]. A similar situation was recorded in Ruditapes decussatus infected by Perkinsus olseni. The glutation s-transferase is also an antioxidant needed to protect the host cells from oxidative burst and it was found down-regulated. In addition, genes related to the cytoskeleton were up-regulated, suggesting a high necessity for entrap microorganisms [105]. 
Proteomic analyses are a complementary approach to the transcriptomics because discrepancies between transcription (mRNA level) and translation (protein level) due to post-transcriptional and post-translational changes cannot be predicted from genomic or mRNA sequences yet [106]. Proteomics has been used in cephalopods to study the immune system from a pathological or ecological perspective $(59,104,107]$. Concerning pathological effects, the interaction between A. octopiana and $O$. vulgaris has recently provided the first insights about the effect of the coccidian at proteomic level. In octopus with high coccidian load a rising phagocytic activity has been observed [69]. This result agreed with up-regulation of the cytoskeletal proteins actin, filamin and fascin in haemocytes of octopus with high parasite load [104]. In addition, the protein fascin has

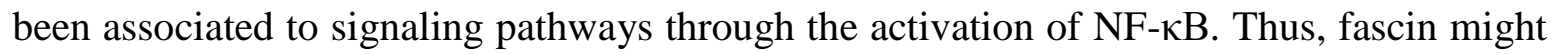
be also taking part in regulation of the immune response [108]. Moreover, based on principal analysis component, seven proteins (sodium channel, fascin, glutamate DH, 6phosphogluconolacton, peroxiredoxin, filamin, ATP synthase) were found contributing significantly to explain the alteration of such proteins in octopus with high or low coccidian load. However, these proteins need to be studied in detail in order to reveal their potential role as biomarkers of infection [104]. The molecular knowledge obtained at transcriptomic and proteomic level is expected to be applied for identification of molecular biomarkers of octopus resistance to coccidiosis and to develop non-invasive methods of pathogen detection that help to improve octopus aquaculture.

From ecological standpoint, the interaction between the sepiolid E. scolopes and their symbiont $V$. fischeri have been widely studied providing interesting results that have been comprehensively explained by Rader and Nyholm [109]. Therefore, we will mention 
briefly a couple of notable works because their contributions helped to establish the molecular bases of such interaction. One of these works belongs to Schleicher and Nyholm [107] who carried out a proteomic approach in order to identified proteins of the symbiotic bacteria and also the cephalopod host. Proteins like luciferase alkyl hydroperoxide reductase C22, catalase, superoxide dismutase, thioredoxin peroxidase were identified in the $V$. fischeri proteome. Concerning the host, several proteins involved in immune defense were found such as peptidoglycan recognition proteins, galectin, superoxide dismutase, peroxiredoxin and proteins involved in the NF- $\kappa \mathrm{B}$ signaling as well [108]. The finding suggests that common immune mechanisms like peptidoglycan recognition, C3 precursor components among others are activated in response to all different bacteria (not only $V$. fischeri) that penetrates to the host light organ. Thus, signaling pathways or respiratory burst is activated in order to avoid colonization of non-symbiotic bacteria. At the same time host and symbiont expressed antioxidant proteins like peroxinitrite and catalase, respectively, in order to be protected against the host defensive mechanisms [108]. Other proteins like BIP (permeability-increasing protein), (found in neutrophils, secretions, epithelia of intestine) also found in E. scolopes haemocytes [102], might avoid the establishment of non-symbiotic bacteria. Undoubtedly, the work performed by Collins et al. [59] is one of the most significant performed due to the combination of transcriptomics and proteomics of haemocytes. In total, 596 sequences were found in transcriptome and proteome, while 145 sequences could only be identified by proteomics. This work allowed the identification of new genes involved in several functions, including the immune response. Among these, a new PGRP termed EsPGRP5 was found, and presumably, it is capable to degrade bacterial peptidoglycan and its derivatives. Additional transcripts found corresponded to the Toll/NF- $\kappa \mathrm{B}$ pathway, cytotoxic response, complement cascade, IK 
cytokine and even a CD63 antigen. In agreement with Collins et al. [59] more studies need to be conducted by combining transcriptomic and proteomic approaches in order to complement the gene/protein identification using both methods when possible and to obtain a more complete overview of the immune system.

Additionally to the "omics" analysis yet performed, new fields of study are being applied lately to cephalopods. Such is the case of epigenetics modifications, referred to changes in gene expression without altering the DNA sequence [110]. First results indicate that the genome of $\mathrm{O}$. vulgaris is widely methylated, but cytosine methylation in CCGG sites is not tissue specific. No differences were found between octopus sexes. In contrast, some differences were found in the mantle of specimens at different stage of maturity, probably because biochemical changes related to reproduction [111]. One of the most interesting findings is the methylation pattern found in the common octopus paralarvae, higher than those observed in adult animals [111]. This result suggests that methylation might have a role in the octopus development as it has been shown for Crasosstrea gigas [112]. Therefore, gene silence or activation mediated by cytosine methylation is suggested at paralarval stage, when it is more susceptible to predators and food availability, but also major morphological changes occur. At this stage, the environmental conditions and nutrition might affect the gene transcription through epigenetic mechanisms [111]. Thus, epigenetic mechanism may play a role in regulation of the octopus early development and probably their immune system, affecting health and survival. Further attempts to develop methylation as a line of research in cephalopods could improve the future cephalopod aquaculture. 


\section{Concluding remarks}

The recent knowledge confronts to the old data widely accepted until now, since new studies confirm the identification of different types of circulating cells in the cephalopod haemolymph. The evidence however suggests that not all cephalopods carry more than one single type of haemocytes. Therefore, the study of additional cephalopod species is needed in order to make clear if the presence of one or more types of haemocytes is linked to ecologic or evolutionary differences among cephalopod species. In addition, is highly important to standardize the morphological and/or functional features that will be used to characterize the cephalopod haemocytes and the nomenclature that will be applied in order to avoid confusion. Concerning the molecular immunity overview here mentioned, few works related to the topic has been published. However, the current data demonstrate a wide repertoire of molecules involved in recognition, signaling and apoptotic pathways. These findings suggest that genes involved in the cephalopod immune defense show high similarity to those that participate in the vertebrate immune response. The finding of such molecules that presumably are specific of highly evolved animals could be indicative that similar mechanisms may be occurring in phylogenetic distant animals such as cephalopods, and suggesting that the immune system of cephalopods could be more complex than expected. However, the differences cannot be established unless more knowledge is reached. Further knowledge will let us understand the evolution of innate immune mechanisms in molluscan and the role that cephalopods play on it. Certainly, disclosure and characterization of novel genes involved in defensive activities could provide more molecules like antimicrobial peptides, TLR receptors, among others, with possible application in aquaculture of cephalopods. 


\section{References}

[1] Uriarte I, Iglesias J, Domingues P, Rosas C, Viana MT. Current status and bottle neck of octopod aquaculture: the case of American species. J. World Aquac. Soc. 2011; 42 (6): 735-752.

[2] Iglesias J, Fuentes L, Villanueva R. Cephalopod Culture. Iglesias et al. eds. 2014; pp. 279. Springer Netherlands.

[3] Vaz- Pires P, Seixas P, Barbosa A. Aquaculture potential of the common octopus (Octopus vulgaris Cuvier, 1797): a review. Aquaculture. 2004; 238: 221-238.

[4] Gestal C, Prado-Alvarez M, García P, Iglesias, J, Otero, JJ, Almansa E. Transcriptome of the first life stages of the common octopus (Octopus vulgaris). Study of epigenetic regulation and biomarkers of welfare and health on the OCTOWELF project. ISDCI Congress. Murcia, June2015.

[5] Grant P, Zheng Y, Pant H. Squid (Loligo pealei) giant fiber system. A model for studying neurodegeneration and dementia?. Biol. Bull. 2006; 210:318-333.

[6] Hochner B. Octopuses. Curr. Biol. 2008; 18: R897-R898.

[7] Zullo L, Hochner B. A new perspective on the organization of an invertebrate brain. Commun. Integr. Biol. 2011; 4: 26-29.

[8] Borrelli L, Fiorito G. Behavioral analysis of learning and memomry in cephalopods. In: Byrne JJ, (ed). Learning and Memory: A comprehensive reference. Oxford: Academic Press. 2008; pp. 605-627. 
[9] Hochner B. An embodied view of octopus neurobiology. Curr. Biol. 2012; 22: R887-R892.

[10] European Directive 2010/63/EU. European Commission. Implementation, interpretation and terminology of Directive 2010/63/EU - Q\&A document. Brussels: European Commission, 2014; pp. 49.

[11] Crook RJ, Lewis T, Hanlon RT, Walters ET. Peripheral injury induces long-term sensitization of defensive responses to visual and tactile stimuli in the squid Loligo pealeii, Lesueur 1821. J Exp. Bio.l. 2011; 214:3173-3185.

[12] Andrews PLR, Darmaillacq AS, Dennison N, Gleadall IG, Hawkins P, Messenger JB, Osorio D, SmithVJ Smith JA. The identification and management of pain, suffering and distress in cephalopods, including anesthesia, analgesia and humane killing. $\mathbf{J}$ Exp. Mar. Biol. Ecol. 2013; 447: 46-64.

[13] Alupay JS, Hadjisolomou SP, Crook RJ. Arm injury produces long-term behavioral and neural hypersensitivity in octopus. Neurosci Lett. 2013; 558: 137-142.

[14] Smith JA, Andrews PLR, Hawkins P, Louhimies S, Ponte G, Dickel L. Cephalopod research and EU Directive 2010/63/EU: Requirements, impacts and ethical review. J Exp. Mar. Biol. Ecol. 2013; 447: 31-45.

[15] Moltschaniwskyj N, Hall K, Marian J, Nishiguchi M, Sakai M, et al. Ethical and welfare considerations when using cephalopods as experimental animals. Rev. Fish Biol. Fisheries. 2007; 17:455-476.

[16] Fiorito G, Affuso A, Basil J, Cole A, Girolamo P, et al. Guidelines for the care and welfare of cephalopods in research. A consensus based on an initiative by CephRes, FELASA and the Boyd Group. Laboratory Animals. In press, 2015. 
[17] Sykes AV, Gestal C. Welfare and diseases under culture conditions. In: J. Iglesias et al. (eds.), Cephalopod Culture. 2014; pp. 97-112. Springer Netherlands.

[18] Hanlon RT, Forsythe JW. Diseases of Mollusca: Cephalopoda. Diseases caused by Microorganisms. In: Kinne O, editor. Diseases of Marine Animals. Volume III Introduction, Cephalopoda, Annelida, Crustacea, Chaetognatha, Echinodermata, Urochordata. Hamburg, Germany: Biologische Anstalt, Helgoland. 1990a; pp. 23-46.

[19] Hanlon RT, Forsythe JW. Diseases of Mollusca: Cephalopoda. Structural abnormalities and neoplasia. In: Kinne O, editor. Diseases of Marine Animals. Volume III Introduction, Cephalopoda, Annelida, Crustacea, Chaetognatha, Echinodermata, Urochordata. Hamburg, Germany: Biologische Anstalt, Helgoland. 1990 b; pp. 203-228.

[20] Hochberg FG. Diseases of Mollusca: cephalopoda. Diseases caused by protistans and Metazoans. In: Kinne O, editor. Diseases of Marine Animals. Volume III Introduction, Cephalopoda, Annelida, Crustacea, Chaetognatha, Echinodermata, Urochordata. Hamburg, Germany: Biologische Anstalt, Helgoland. 1990; pp. 47-202.

[21] Rungger D, Rastelli M, Braendle E, Malsberg RG.Viruslike particle associated with lesions in muscles of Octopus vulgaris. J Invert. Pathol. 1971; 17: 72-80.

[22] Gomez DK, Baeck GW, Kim JH, Choresca CH, Park SC. Genetic analysis of betanodaviruses in subclinically infected aquarium fish and invertebrates. Curr. Microbiol. 2008; 56: 499-504.

[23] Hanlon RT, Forsythe JW, Cooper KM, Dinuzzo AR, Folse DS, Kelly MT. Fatal penetrating skin ulcers in laboratory-reared octopuses. J. Invertebr. Pathol. 1984; 44: $67-83$. 
[24] Ford LA, Alexander SK, Cooper KM, Hanlon RT. Bacterial populations of normal and ulcerated mantle tissue of the squid, Lolliguncula brevis. J. Invertebr. Pathol. 1986; 48: $13-26$.

[25] Farto R, Armada SP, Montes M, Guisande JA, Pérez MJ, Nieto TP. Vibrio lentus associated with diseased wild octopus (Octopus vulgaris). J Invert. Pathol. 2003; 83: $149-156$.

[26] Poynton SL, Reimschuessel R, Stoskopf MK. Aggregata dobelli n. sp. and Aggregata millerorum n. Sp. (Apicomplexa, Aggregatidae) from two species of octopus (Mollusca, Octopodidae) from the Eastern North Pacific-Ocean. J. Protozool. 1992; 39 (1058): 248-256.

[27] Gestal C, Abollo E, Pascual S. Observations on associated histopathology with Aggregata octopiana infection (Protista: Apicomplexa) in Octopus vulgaris. Dis. Aquat. Org. 2002a; 50: 45-49.

[28] Gestal C, Guerra A, Pascual S. Aggregata octopiana (Protista: Apicomplexa): a dangerous pathogen during commercial Octopus vulgaris ongrowing. ICES J. Mar. Sci. 2007; 64: 1743-1748.

[29] Gestal C, de la Cadena MP, Pascual S. Malabsorption syndrome observed in the common octopus Octopus vulgaris infected with Aggregata octopiana (Protista: Apicomplexa). Dis. Aquat. Org. 2002b; 51: 61-65.

[30] Mladineo I, Jozic M. Aggregata infection in the common octopus, Octopus vulgaris (Linnaeus 1758), Cephalopoda: Octopodidae, reared in a flow-through system. Acta Adriat. 2005; 46: 193-199. 
[31] Mladineo I, Bocina I. Extraintestinal gamogony of Aggregata octopiana in the reared common octopus (Octopus vulgaris) (Cephalopoda: Octopodidae). J. Invertebr. Pathol. 2007; 96: 261-264.

[32] Kopecná J, Jirkú M, Oborník M, Tokarev YS, Lukes J, Modry D. Phylogenetic analysis of coccidian parasites from invertebrates: search for missing links. Protist. 2006; 157: 173-183.

[33] Pascual S, Gestal C, Estévez JM, Rodriguez H, Soto M, Abollo E, Arias C. Parasites in commercially-exploited cephalopods (Mollusca, Cephalopoda) in Spain: an updated perspective. Aquaculture. 1996a; 142: 1-10.

[34] Pascual S, Gonzalez AF, Arias C, Guerra A. Biotic relationships of Illex coindetii and Todaropsis eblanae (Cephalopod, Ommastrephidae) in the North East Atlantic: evidence from parasites. Sarsia. 1996b; 81: 265-274.

[35] Petrić M, Mladineo I, Krstulović Šifner S. Insight into the short-finned squid Illex coindetii (Cephalopoda: Ommastrephidae) feeding ecology: is there a link between helminth parasites and food composition? J. Parasitol. 2011; 97: 55-62.

[36] Pardo-Gandarillas MC, Lohrmann KB, Valdivia AL, Ibáñez ChM. First record of parasites of Dosidicus gigas (d' Orbigny, 1835) (Cephalopoda: Ommastrephidae) from the Humboldt Current system off Chile. Rev. Biol. Mar. Oceanogr. 2009; 44: 397-408.

[37] Overstreet R, Hochberg FG. Digenetic trematodes in cephalopods. J. Mar. Biol. Ass. U.K. 1975; 55: 893-910. 
[38] Takahara H, Sakurai Y. Infection of the Japanese common squid, Todarodes pacificus (Cephalopoda: Ommastrephidae) by larval anisakid nematodes. Fish. Res. 2010; 106: $156-159$.

[39] Setyobudi E, Jeon CH, Choi K, Lee SI, Lee CI, Kim JH. Molecular identification of anisakid nematodes third stage larvae isolated from common squid (Todarodes pacificus) in Korea. Ocean Sci. J. 2013; 48(2): 197-205.

[40] Pascual S, Gestal C, Abollo E. Effect of Pennella sp. (Copepoda, Pennellidae) on the condition of Illex coindetii and Todaropsis eblanae (Cephalopoda, Ommastrephidae). Bull. Eur. Assoc. Fish Pathol. 1997; 7: 91-95.

[41] Pascual S, Gonzalez AF, Gestal C, Abollo E, Guerra A. Epidemiology of Pennella sp. (Crustacea: Copepoda), in exploited Illex coindetii stock in the NE Atlantic. Sci. Mar. 2001; 65: 307-312.

[42] Pascual S, Vega MA, Rocha FJ, Guerra A. First report of an endoparasitic epicaridean isopod infecting cephalopods. J. Wildl. Dis. 2002; 38: 473-477.

[43] Pascual S, Guerra A. Vexing question on fisheries research: the study of cephalopods and their parasites. Iberus. 2001; 19(2): 87-95.

[44] Wells MJ, Smith PJS. The performance of the Octopus circulatory system: a triumph of engineering over design. Experientia. 1987; 43: 487-499.

[45] Cowden RR. Some cytological and cytochemical observations on leukopoietic organs, the "white bodies" of Octopus vulgaris. J. Invertebr. Pathol. 1972; 19: 113119. 
[46] Claes MF. Functional morphology of the white bodies of the cephalopod mollusk Sepia officinalis. Acta Zool. 1996; 77: 173-190.

[47] Cazal P, Bogaraze D. Recherches sur les corps blanc du poulpe (Octupus vulgaris, Lam.). Leur fonction globuligéne et néphrocitaire. Bull. Inst. Océanogr. Monaco, 40(842). 1943. 1-12.

[48] Necco A, Martin R. Behavior and estimation of the mitotic activity of the white body cells in Octopus vulgaris cultured in vitro. Exp. Cell Res. 1963; 30: 588-590.

[49] Stuart AE. The reticulo-endothelial apparatus of the lesser octopus, Eledone cirrosa. J Pathol. Bacteriol. 1968; 96: 401-412.

[50] Cowden RR, Curtis SK. Cephalopods. In: Ratcliffe, N.A., Rowley, A.F. (Eds.), Invertebrate blood cells. General Aspects, animals without true circulatory systems to cephalopods, 1. 1981; Academic Press, London, UK, pp. 301-323.

[51] Ford LA. Host defense mechanisms of cephalopods. Annu. Rev. Fish Dis. 1992; 2: $25-41$.

[52] Malham SK, Runham NW. A brief review of the immunology of Eledone cirrhosa. S. Afr. J. Mar. Sci. 1998a; 20: 385-391.

[53] Malham SK, Runham NW, Secombes Ch J. Lysozyme and antiprotease activity in the lesser octopus Eledone cirrhosa (Lam.) (Cephalopoda). Dev. Comp. Immunol. 1998b; 22: $27-37$. 
[54] Cowden RR, Curtis SK. Observations on living cells dissociated from leukopoietic organ of Octopus briareus. Exp. Mol. Pathol. 1973; 19: 178-185.

[55] Novoa B, Tafalla C, Guerra A, Figueras A. Cellular immunological parameters of the octopus, Octopus vulgaris. J. Shellfish. Res. 2002; 21: 243-248.

[56] Kondo M, Tomonaga S, Takahashi Y. Morphology of octopus hemocytes. J. Natl. Fish. Univ. (Japan) 2003; 4: 157-164.

[57] Castellanos-Martínez S, Prado-Alvarez M, Lobo-da-Cunha A, Azevedo C, Gestal C. Morphologic, cytometric and functional characterization of the common octopus (Octopus vulgaris) hemocytes. Dev. Comp. Immunol. 2014c; 44(1):50-8.

[58] Troncone L, De Lisa E, Bertapelle C, Porcellini A, Laccetti P, Polese G, Di Cosmo A. Morphofunctional characterization and antibacterial activity of haemocytes from Octopus vulgaris. J. Nat. Hist. 2014; doi.org/10.1080/00222933.2013.826830

[59] Collins AJ, Schleicher TR, Rader BA, Nyholm SV. Understanding the role of host hemocytes in a squid/Vibrio symbiosis using transcriptomics and proteomics. Front. Immunol. 2012; 10(3):91. doi: 10.3389/fimmu.2012.00091. eCollection 2012.

[60] Bolognari A. Morfologia, struttura e funzione del "corpo bianco" dei cefalopodi. I. Morfologia. Arch. Zool. Ital. 1949; 34, 78-97.

[61] Le Pabic C, Goux D, Guillamin M, Safi G, Lebel JM, Koueta N, Serpentini A. Hemocyte morphology and phagocytic activity in the common cuttlefish (Sepia officinalis). Fish Shellfish Immunol. 2014a; 40: 362-373. 
[62] Ashton-Alcox KA, Ford SE. Variability in molluscan hemocytes: a flow cytometric study. Tissue Cell 1998; 30: 195-204.

[63] Allam B, Ashton-Alcox KA, Ford SE. Flow cytometric comparison of haemocytes from three species of bivalve molluscs. Fish Shellfish Immunol. 2002; 13: 141-158. http://dx.doi.org/10.1006/fsim.2001.0389.

[64] Mayrand E, St Jean SD, Courtenay SC. Haemocyte responses of blue mussels (Mytilus edulis L.) transferred from a contaminated site to a reference site: can the immune system recuperate? Aquac. Res. 2005; 36: 962-971.

[65] Da Silva PM, Comesaña P, Fuentes J, Villalba A. Variability of haemocyte and haemolymph parameters in European flat oyster Ostrea edulis families obtained from brood stocks of different geographical origins and relation with infection by the protozoan Bonamia ostreae. Fish Shellfish Immunol. 2008; 24: 551-563.

[65] Flye-Sainte-Marie J, Soudant P, Lambert Ch, Le Go N, Goncalvez M, et al. Variability of the hemocyte parameters of Ruditapes philippinarum in the field during an annual cycle. J. Exp. Mar. Biol. Ecol. 2009; 377 (1): 1-11.

[66] Allam B, Ford SE. Effects of the pathogenic Vibrio tapetis on defence factors of susceptible and non-susceptible bivalves species: I. Haemocytes changes following in vitro challenge. Fish Shellfish Immunol. 2006; 20: 374-383.

[67] Castellanos-Martínez S, Gestal C Pathogens and immune response of cephalopods. J. Exp. Mar. Biol. Ecol. 2013; 447: 14-22. 
[68] Mayo-Hernández E, Barcala E, Berriatua E, García-Ayala A, Muñoz P. Aggregata (Protozoa: Apicomplexa) infection in the common octopus Octopus vulgaris from the West Mediterranean Sea: The infection rates and possible effect of faunistic, environmental and ecological factors. J. Sea Res. 2013; 83: 195-201.

[69] Castellanos-Martinez, S, Gestal C. Immune response of Octopus vulgaris against the infection by the gastrointestinal parasite Aggregata octopiana. J. Shellfish. Res. 2011; 30, 997-998.

[70] McFall-Ngai MJ, Nyholm SV, Castillo MG. The role of the immune system in the initiation and persistence of the Euprymna scolopes-Vibrio fischeri symbiosis. Semin. Immunol. 2010; 22: 48-53.

[71] Grimaldi AM, Belcari P, Pagano E, Cacialli F, Locatello L. Immune responses of Octopus vulgaris (Mollusca: Cephalopoda) exposed to titanium dioxide nanoparticles. J. Exp. Mar. Biol. Ecol. 2013; 447: 123-127.

[72] García-García E, Prado-Alvarez M, Novoa B, Figueras A, Rosales C. Immune responses of mussel hemocyte subpopulations are differentially regulated by enzymes of the PI 3-K, PKC, and ERK kinase families. Dev. Comp. Immunol.32, 2008, 637653.

[73] Donaghy L, Kim BK, Hong HK, Park HS, Choi KS. Flow cytometry studies on the populations and immune parameters of the hemocytes of the Suminoe oyster Crassostrea ariakiensis. Fish Shellfish Immunol. 2009; 27: 296-301. 
[74] Donaghy L, Hong HK, Lambert C, Park HS, Shim WJ, Choi KS. First characterization of the populations and immune-related activities of hemocytes from two edible gastropod species, the disk abalone, Haliotis discus discus and the spiny top shell, Turbo cornutus. Fish Shellfish Immunol. 2010; 28: 87-97.

[75] Prado-Alvarez M, Romero A, Balseiro P, Dios S, Novoa B, Figueras A. Morphological characterization and functional immune response of the carpet Shell clam (Ruditapes decussatus) haemocytes after bacterial stimulation. Fish Shellfish Immunol. 2012; 32: 69-78.

[76] Rodríguez-Domínguez H, Soto-Búa M, Iglesias-Blanco R, Crespo-González C, AriasFernández C, García-Estévez J. Preliminary study on the phagocytic ability of Octopus vulgaris Cuvier, 1797 (Mollusca: Cephalopoda) haemocytes in vitro. Aquaculture. 2006; 254: 563-570.

[77] Beuerlein K, Lohr S, Westermann B, Ruth P, Schipp R. Components of the cellular defense and detoxification system of the common cuttlefish Sepia officinalis (Mollusca, Cephalopoda). Tissue and Cell. 2002; 34(6): 390-396.]

[78] Ellis R, Parry H, Spicer JI, Hutchinson T, Pipe R, Widdicombe S. Immunological function in marine invertebrates: responses to environmental perturbation. Fish Shellfish Immunol. 2011; 30: 1209-1222.

[79] Vidal AGE, Villanueva R, Andrade JP, Gleadall IG, Iglesias J, et al. Cephalopod culture: current status of main biological models and research priorities. In: J. Iglesias et al. (eds.), Cephalopod Culture. 2014; pp. 2-79. Springer Netherlands. 
[80] Lacoue-Labarthe T, Warnau M, Oberhänsli F, Teyssié JL, Koueta N, Bustamante P. Differential bioaccumulation behaviour of $\mathrm{Ag}$ and $\mathrm{Cd}$ during the early development of the cuttlefish Sepia officinalis. Aquat. Toxicol. 2008b; 18:86(3):437-46.

[81] Lacoue-Labarthe T, Warnau M, Oberhänsli F, Teyssié JL, Jeffree R, Bustamante P. First experiments on the maternal transfer of metals in the cuttlefish Sepia officinalis. Mar. Pollut. Bull. 2008a; 57(6-12):826-31.

[82] Miramand P, Bustamante P, Bentley D, Koueta N. Variation of heavy metal concentrations ( $\mathrm{Ag}, \mathrm{Cd}, \mathrm{Co}, \mathrm{Cu}, \mathrm{Fe}, \mathrm{Pb}, \mathrm{V}$, and $\mathrm{Zn}$ ) during the life cycle of the common cuttlefish Sepia officinalis. Sci. Total Environ. 2006; 361: 132-143.

[83] Raimundo J, Costa PM, Vale C, Costa MH, Moura I. Metallothioneins and trace elements in digestive gland, gills, kidney and gonads of Octopus vulgaris. Comp. Biochem. Physiol. C. 2010; 152: 139-146.

[84] Scown TM, Van Aerle R, Tyler CR. Review: do engineered nanoparticles pose a significant threat to the aquatic environment? Crit. Rev. Toxicol. 2010; 40(7): 653670.

[85] Canesi L, Frenzilli G, Balbi T, Bernardeschi M, Ciacci C, et al. Interactive effects of nTiO2 and 2,3,7,8-TCDD on the marine bivalve Mytilus galloprovincialis. Aquat. Toxicol. 2014; 153: 53-65.

[86] Baker TJ, Tyler CR, Galloway TS. Impacts of metal and metal oxide nanoparticles on marine organisms. Environ. Pollut. 2014; 186: 257-271. 
[87] Barmo C, Ciacci C, Canonico B, Fabbri R, Cortese K, et al. 2013. In vivo effects of nTiO 2 on digestive gland and immune function of the marine bivalve Mytilus galloprovincialis. Aquat. Toxicol. 2013; 132-133: 9-18.

[88] Fisher WS, Dinuzzo AR. Agglutination of bacteria and erythrocytes by serum from six species of marine mollusks. J. Invertebr. Pathol. 1991; 57: 380-394.

[89] Ganz T. The role of antimicrobial peptides in innate immunity. Integr.Comp.Biol. $2003 ; 43: 300-304$.

[90] Ramasamy P, Vino AB, Saravanan R, Subhapradha N, Shanmugam V, Shanmugam A. Screening of antimicrobial potential of polysaccharide from cuttlebone and methanolic extract from body tissue of Sepia prashadi Winkworth, 1936. Asian Pac. J.Trop. Biomed. 2011; S244-S248.

[91] Mohanraju R, Marri DB, Karthick P, Narayana S, Murthy KN, Ramesh Ch. Antibacterial activity of certain cephalopods from Andamans, India. IJPBS. 2013; 3(2): 450-455.

[92] Monolisha S, Mani AE, Patterson J, Patterson JKE. Molecular characterization and antimicrobial activity of Octopus aegina and Octopus dolfusii in Gulf of Mannar coast. IJPSR. 2013; 4(9): 3582-3587.

[93] Sadayan P, Thiyagarajan S, Balakrishnan B. Inhibitory activity of ink and body tissue extracts of Euprymna stenodactyla and Octopus dollfusi aganist histamine producing bacteria. Middle East J. Sci. Res. 2013; 16 (4): 514-518. 
[94] Vino AB, Shanmugam V, Shanmuga A. Antimicrobial activity of methanolic extract and fractionated polysaccharide from Loligo duvauceli Orbingy 1848 and Doryteuthis sibogae Adam 1954 on human pathogenic microorganisms. African Afr J. Microbiol. Res. 2014; 8(3): 230-236.

[95] Cerenius L, Söderhäll K. The prophenoloxidase-activating system in invertebrates. Immunol. Rev. 2004; 198:116-126.

[96] Le Pabic C, Safi G, Serpentini A, Lebel JM, Robin JP, Koueta N. Prophenoloxidase system, lysozyme and protease inhibitor distribution in the common cuttlefish Sepia officinalis. Comp. Biochem. Physiol B Biochem. Mol. 2014b; 172-173B:96-104. Part B 172-173: 96-104.

[97] Albertin CB, Bonnaud L, Brown TC, Crookes-Goodson WJ, da Fonseca RR et al. Cephalopod genomics: a plan of strategies and organization. Stand Genomic Sci. 2012; 7: 175-188.

[98] Castellanos-Martínez S, Arteta D, Catarino S, Gestal C. De Novo transcriptome sequencing of the Octopus vulgaris hemocytes Using Illumina RNASeq.Technology: response to the infection by the gastrointestinal parasite Aggregata octopiana. PLoS ONE 2014a; 9(10): e107873. doi:10.1371/journal.pone.0107873

[99] Moreira R, Balseiro P, Planas JV, Fuste B, Beltran S, et al. Transcriptomics of in vitro immune-stimulated hemocytes from the manila clam Ruditapes philippinarum using high-throughput sequencing. PloS One. 2012; 7: e35009. 
[100] Alpuche J, Pereyra A, Mendoza-Hernandez G, Agundis C, Rosas C, Zenteno E. Purification and partial characterization of an agglutinin from Octopus maya serum. Comp. Biochem. Physiol. B: Biochem. Mol. Biol. 2010: 156: 1-5.

[101] Goodson MS, Kojadinovic M, Troll JV, Scheetz TE, Casavant TL, Soares MB, McFall-Ngai MJ. Identifying components of the NF-kappa B pathway in the beneficial Euprymna scolopes Vibrio fischeri light organ symbiosis. Appl. Environ. Microbiol. 2005; 71: 6934-6946.

[102] Krasity BC, Troll JV, McFall-Ngai MJ. Responses of host hemocytes during the initiation of the squid-Vibrio symbiosis. Biol Bull. 2011; 212: 29-39.

[103] Wei X, Xu J, Yang J, Liu X, Zhang R, Wang W, Yang J. Involvement of a Serpin serine protease inhibitor (OoSerpin) from mollusc Octopus ocellatus in antibacterial response. Fish Shellfish Immunol. 2015; 42(1):79-87.

[104] Castellanos-Martínez S, Diz AP, Álvarez-Chaver P, Gestal C. Proteomic characterization of the hemolymph of Octopus vulgaris infected by the protozoan parasite Aggregata octopiana. J Proteomics. 2014b; 13(105):151-63. doi: 10.1016/j.jprot.2013.12.008.

[105] Leite RB, Milan M, Coppe A, Bortoluzzi S, dos Anjos A, et al. mRNA-Seq and microarray development for the Grooved carpet shell clam, Ruditapes decussatus: a functional approach to unravel host -parasite interaction. BMC Genomics. 2013;14: 741. 
[106] Diz AP, Martínez-Fernandez M, Rolán-Alvarez E. Proteomics in evolutionary ecology: linking the genotype with the phenotype. Mol Ecol. 2012; 21(5):1060-80.

[107] Schleicher TR, Nyholm S. Characterizing the host and symbiont proteomes in the association between the bobtail squid, Euprymna scolopes, and the bacterium, Vibrio fisheri. PloS One. 2011; 6: e25649.

[108] Feng Y, Walsh CA. The many faces of filamin: a versatile molecular scaffold for cell motility and signaling. Nat. Cell Biol. 2004; 6:1034-8.

[109] Rader BA, Nyholm S. Host/microbe interactions revealed through "omics" in the symbiosis between the Hawaiian bobtail squid Euprymna scolopes and the bioluminescent bacterium Vibrio fischeri. Nat. Rev. Microbiol.2012; 19(12): 815-27.

[110] Richards EJ. Inherited epigenetic variation - revisiting soft inheritance. Nature. Review. Genetics. 2006; 7: 395-340.

[111] Díaz-Freije E, Gestal C, Castellanos-Martínez S, Morán P. The role of DNAmethylation on Octopus vulgaris development and their perspectives. Front. Physiol. 2014; 5(62). doi:10.3389/fphys.2014.00062

[112] Riviere G, Wu GC, Fellous A, Goux D, Sourdaine P, Favrel P. DNA methylation is crucial for the early development in the oyster C. gigas. Marine Biotechnol. 2013; $1-15$. 


\section{Figure Legends}

Figure 1. Octopus vulgaris reared in on-growing cages in Ria of Vigo (Galicia, Spain) (Courtesy of Rubén Chamorro).

Figure 2. Different types of haemocytes found in O. vulgaris haemolymph from NE Atlantic observed by Scanning Electron Microscopy (SEM). (A) Large granulocytes, (B) Small granulocytes.

Figure 3. Haemocytes showing differences in size and granularity. (A) Comparative of $O$. vulgaris haemocytes observed in fresh haemolymph and (B) haemolymph cell monolayers observed by SEM. (C) (5,300x) and (D) (8,000x) TEM micrographs of O. vulgaris circulating haemocytes.

Figure 4. Phagocytic capability of $O$. vulgaris haemocytes observed by SEM. (A) Haemocytes surrounding sporocyst of coccidia Aggregata octopiana. (B) Haemocytes of $O$. vulgaris phagocytizing fluorescent latex beads (Original).

Figure 5. Complement and clotting pathway. Brown figures indicate proteins identified in the $O$. vulgaris library; and blue figures indicate the absent ones. C1q: Complement $\mathrm{C} 1 \mathrm{q}$ binding protein; C1R: C1r subcomponent; C1S: Complement $\mathrm{C} 1$ subcomponent; C2: Complement component 2; C4: Complement component 4; C3: Complement component 3; C3a: anaphylatoxin subcomponent 3a; C3b: Opsonin subcomponent 3b; C5: Complement component; C3R: C3 receptor; C5R: C5 receptor; MBL: Manose-binding lectin; MASP1/2: Mannan-binding lectin serine protease 1/2; F12: factor 12; F11: Factor 11; $\alpha 2 \mathrm{M}$ : Alphamacroglobulin; F2,3,5,7,8,9,10: Coagulation factors 2,3,5,7,8,9,10; MPC: CD46, 
membrane cofactor protein; VWF: Von Willebrand factor; KLKB1: kallikrein B1; PROC: protein C; PROS1: protein S (alpha); THBD: trombomodulin.

Figure 6. 2-DE protein pattern of Octopus vulgaris haemocytes. (A) General proteome pattern of the $O$. vulgaris haemocytes of a healthy specimen showing the location of spot peroxiredoxin (white circle). Comparison of the spot of peroxiredoxin in healthy specimens (B) against a faint spot in sick octopus (Original) (C). 